\title{
Scintigraphic evaluation and prognosis of patients with Reiter's syndrome
}

\author{
A. S. RUSSELL, M. J. BUTLER, AND B. C. LENTLE \\ From the University Hospital and the W.W. Cross Cancer Institute, Edmonton, Alberta, Canada
}

Knowledge of the association of Reiter's syndrome (RS) with the genetic marker HLA-B27 has not only given us a useful diagnostic tool but has also heightened our awareness of the association of this disease with ankylosing spondylitis (AS). This association has been recognised clinically for very many years. ${ }^{134} \mathrm{~A}$ number of authors thought that under these circumstances AS could be regarded as a complication of RS. The proportion of such patients recognised depends on the duration of follow-up but could well be of the order of $25 \% 0^{135}$ This figure is very similar to the reported prevalence of sacroiliitis seen on screening B27-positive blood donors. ${ }^{54}$ It could therefore be argued that the association of AS with RS is no more than purely coincidental, since both are largely dependent on the presence of HLAB27. It is our own prejudice that this is not so, and there is some clinical evidence to support this view.

We have looked at the sacroiliac scintiscans in patients with RS to see if we can show that sacroiliac changes are a common if not integral part of this disease.

\section{Patients and methods}

We have reviewed the records of patients with acute RS seen at the Edmonton rheumatic diseases unit
Table 1 Criteria used for diagnosing Reiter's syndrome

Arthritis

Urethritis, mucocutaneous lesions, conjunctivitis/uveitis

(1) Definite = arthritis plus two of remainder

(2) Probable =arthritis plus one of remainder

in the years 1971 to 1978 . Forty-eight fitted the criteria for the disease (Table 1). When first seen they had acute RS. Indeed, any patient with a past history suggestive of RS but who presented at first examination as frank AS was excluded from the study. All were over 22 years of age.

To date, we have re-examined 38 patients, including a pelvic radiograph and a bone scan with ${ }^{99} \mathrm{~m}$ technetium stannous pyrophosphate. Not all the patients had had these investigations during the acute phase of the disease and these omissions are indicated in Table 2. The radiographs were coded and interpreted by three independent observers. Any discordant views were reconciled by a joint discussion.

A posterior bone scan of the pelvis was done using ${ }^{99}$ mtechnetium stannous pyrophosphate given intravenously at a dose adjusted to body weight. The count was made after a standard delay of $3 \frac{1}{2}$ hours, as previously described. ${ }^{202}$ The count density was

Table 2 Scintiscan appearance in patients with either persistent backache or radiological sacroiliac abnormalities

\begin{tabular}{|c|c|c|c|c|c|c|c|}
\hline \multirow[t]{2}{*}{ Patient No. } & \multicolumn{2}{|c|}{ Backache } & \multicolumn{2}{|c|}{ Sacroiliac abnormalities } & \multicolumn{2}{|l|}{ Scan } & \multirow[t]{2}{*}{$B 27$} \\
\hline & Initial & Follow-up & Initial & Follow-up & Initial & Follow-up & \\
\hline 1 & + & + & - & + & - & - & + \\
\hline 2 & + & + & ND & + & + & + & + \\
\hline 3 & - & + & - & - & + & + & - \\
\hline 4 & + & + & - & + & + & + & + \\
\hline 5 & + & + & - & - & ND & + & + \\
\hline 6 & - & + & - & - & + & + & + \\
\hline 7 & + & + & - & + & + & + & + \\
\hline 8 & + & - & - & + & ND & + & + \\
\hline 9 & + & - & - & + & ND & + & + \\
\hline 10 & - & - & - & + & ND & + & + \\
\hline 11 & + & - & - & + & + & - & + \\
\hline 12 & - & - & + & + & - & - & + \\
\hline 13 & - & - & + & + & + & ND & + \\
\hline 14 & - & - & + & + & + & + & + \\
\hline
\end{tabular}

ND = Not done. 
replayed on video tape and a ratio of sacroiliac to sacral uptake was computed.

\section{Results}

Nineteen of the 38 patients had 'definite' disease. The mean age of onset was 26.7 years, and the average duration of follow-up from the first episode was 5.8 years. When re-examined we were surprised to find only three patients with persistent synovitis. Furthermore, two of them had had the disease for under six months and were essentially still in their first attack (Table 3). The impressive feature was that none of the 27 patients $(71.0 \%)$ in groups $1-3$ had any limitation of their function and many admitted to symptoms only after direct questioning. Even those in group 4 functioned essentially normally most of the time but had intermittent acute episodes of synovitis or backache. Only three patients (including both in group 5) were in functional grade $\mathrm{II}^{296}$ at the time of examination. Nine patients $(23.7 \%)$ in groups 3,4 , and 5 remained on continuous anti-inflammatory medication.

Fifteen out of 28 scans performed during acute disease $(53 \%)$ were abnormal. We were able to repeat this investigation in 22 of these 28 patients, including 12 of the 15 whose scans were initially abnormal. The scans in 5 of these 12 had reverted to normal. None that were initially normal had become abnormal. Scans and radiographs were obtained in the 10 remaining patients who had not had these performed initially. When reviewed 10 of the total 38 patients had radiological abnormalities at one or both sacroiliac joints. In six of these the changes could be shown to have developed since the acute presentation. Five of the six had had an abnormal bone scan. Seven patients had a significant persistent backache with morning stiffness. Six of these had abnormal sacroiliac scintiscans and three had abnormal sacroiliac radiographs.

Table 3 Clinical status at follow-up examination of 38 patients with Reiter's syndrome

\begin{tabular}{llc}
\hline Group & Status & $\begin{array}{l}\text { No. (\%) of } \\
\text { patients }\end{array}$ \\
\hline 1 & Totally asymptomatic & $5(13 \%)$ \\
2 & Minimal arthralgia-intermittent & $9(24 \%)$ \\
3 & $\begin{array}{c}\text { Moderate arthralgia or backache- } \\
\text { intermittent }\end{array}$ & $13(34 \%)$ \\
4 & $\begin{array}{c}\text { Acute arthralgia/arthritis or backache- } \\
\text { intermittent }\end{array}$ & $9 *(24 \%)$ \\
5 & Monarticular synovitis-persistent & $2(5 \%)$ \\
\hline
\end{tabular}

* Only one patient in this group had detectable clinical synovitis at time of review.

\section{Discussion}

It is important to state that an abnormal ${ }^{99 \mathrm{~m} T c}$ isotope uptake expressed as sacroiliac over sacral ratio is not synonymous with the radiological designation of sacroiliitis. Abnormal bone uptake of radionuclide generally reflects abnormal osteoblastic activity or immature collagen. It is abnormal in frank, inflammatory sacroiliitis. But it is also abnormal in osteitis condensans ilii and in a number of people with backache and morning stiffness who over several years have persistently normal radiographs. Thus it indicates an abnormality of these joints, but cannot indicate what sort of abnormality is present. This decision must be made on clinical grounds alone.

It is not merely another way of demonstrating HLA-B27, for we have scanned 12 B27 carriers, of whom six were normal subjects and six suffered from rheumatoid arthritis, and only one scan was abnormal in a patient with rheumatoid arthritis. We think that the abnormal scaroiliac scans often seen in RS are in accordance with the known prevalence of back pain during the acute presentation, ${ }^{134}$ and we suggest that a large proportion of these patients have active sacroiliitis. A few will go on to develop radiological changes as a complication of this, but most, fortunately, remit.

A significant proportion of patients with RS develop areas of diffuse thoracic or thoracolumbar discomfort. These have sometimes been attributed to non-articular disease. Our recent studies with tomographic bone scans using a Pho.Con scanner (Searle) with an Anger tomographic system have allowed us to correlate certain symptoms-such as pain on full inspiration-with an abnormality at one or more costovertebral articulations. Abnormalities of the apophyseal joints may be seen in patients with acute focal back pain both in the acute and chronic stages of the disease. Increased uptake of radionuclide at these areas cannot usually be distinguished on a conventional bone scan. The tomographic scans and routine bone scans are of no diagnostic value in this disease, but they do help further in explaining the mechanisms of some of the clinical problems that are encountered.

\section{General discussion}

DR. J. C. WOodRow: I think Professor Russell has misquoted me. The relationship between Reiter's syndrome and spondylitis is more complex than was thought. I have never denied that in some cases the agent that produces RS may not result in spondylitis. 
What I did report were patients who at their first attack of RS gave a history strongly suggestive of spondylitis and already had sacroiliitis. You say that all your patients with definite sacroiliitis were B27-positive. If most of the cases of spondylitis or sacroiliitis in patients with RS are due to the genetic predisposition implied by $\mathrm{B} 27$ then nearly all these patients should indeed be B27-positive. If, however, the spondylitis was secondary to RS the risk of spondylitis should be equal in the B27-negatives and in the positives.

DR. A. CALIN: Some patients with Reiter's syndrome and ankylosing spondylitis may have both diseases as a manifestation of HLA-B27 rather than one (AS) as a complication of the other.

DR. G. R. V. HUGHES: I would like to support Professor Russell's observations. We are faced with a new sort of clinical problem -the young woman with backache in the absence of B27 or of any $x$-ray changes and a scan with a very high uptake. Therefore we have scanned a series of patients with a variety of causes of low backache. Figs 1 and 2 show the ratio of isotope uptake over the sacroiliac joints to that of the sacrum. The normal range in a large series of controls is up to 1:5-that is, the uptake by the sacroiliac joint normally yields $1 \cdot 5$ times or less that of the sacrum. In ankylosing spondylitis (AS) scanning clearly differentiates clinically active disease from clinically inactive (Fig. 1). While that looks very good for AS the real problem is shown in Fig. 2, which shows different groups of patients.
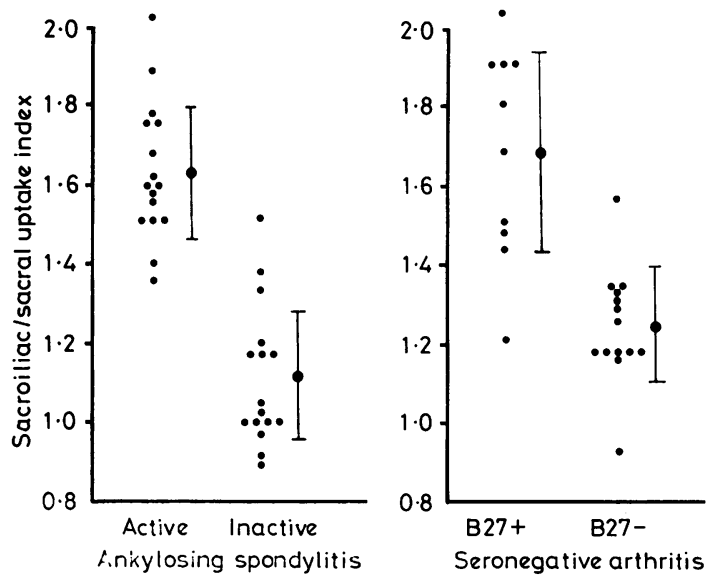

Fig. 1 A ratio of ${ }^{99} \mathrm{~m}_{\text {technetium isotope uptake over }}$ the sacroiliac joints to that over the sacrum. (a) Ankylosing spondylitis: relationship with disease activity, (b) Seronegative arthritis: relationship to the B27 status.

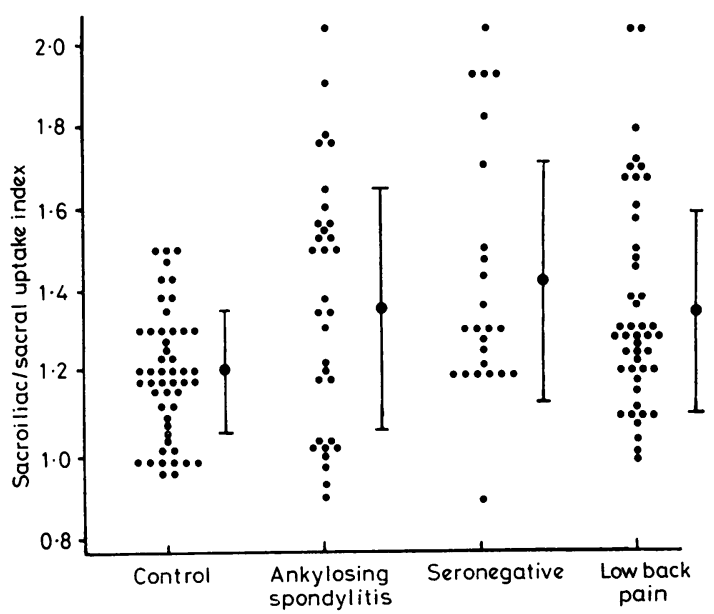

Fig. 2 Sacroiliac/sacral ${ }^{99}$ technetium uptake in ankylosing spondylitis, seronegative arthritis, and presumably non-inflammatory low back pain.

The controls are fairly normal, including patients with wide-spread malignancy not having back pain and with normal serum alkaline phosphatase. The AS patients show the scatter that might be expected but the patients with low back pain (on the basis of degenerative disc disease - that is, noninflammatory back pain) were B27-negative and radiologically negative for sacroiliitis. Almost 50\% of them show abnormal scans. The difficult group of patients are those with serogenative arthritis, where again there is a similar scatter. We separated this group into B27-positive and B27-negative. There was a very clear correlation of abnormal scans in B27-positive peripheral arthritis and of normal in the B27-negative.

So my brief message, like Professor Russell's, is that this is a very sensitive technique but we are not yet able clearly to differentiate patients with backpain. Indeed, we seem to be building up a new type of clinical population of anxious young women with backache who have normal radiographs but abnormal scans.

PROF. RUSSELL: Working with us, Paul Davis has done a very similar study scanning women with backache. These scans have shown that a significant proportion of women who come in as 'neurotic young women' with backache do indeed have an abnormality of their back, perhaps not restricted to the sacroiliac joints. There is no evidence so far of the exact nature of the abnormality and it may well be different from that in AS, although the scans look very similar, but I think it does indicate that they have organic disease. 
PROF. A. T. MASI: Dr. Hughes, were you able to divide your patients with low back pain into B27positive and B27-negative?

DR. HUGHES: Yes, we have done that. We of course went back to all the patients with low back pain with abnormal scans. We re-examined them, $x$-rayed them again, and checked B27 on all. All were B27-negative and radiologically and clinically normal.

DR. CALIN: I entirely agree with Dr. Hughes. Our experience is that this test is over-sensitive and under-specific.

DR. HUGHES: One possibility, of course, is that some of these women may have been B27-negative, true preradiological sacroiliitis.

DR. D. A. BREWERTON: I would like to comment not on the facts but to suggest a different interpretation to your conclusions. In some patients you see acute reactive peripheral arthritis, acute sacroliiitis, and symptomatic spondylitis, while in others there are longer-term effects, with radiographic changes, obvious spondylitis, uveitis, and so on. These may be separate processes, although both may have B27 as a genetic marker. This distinction is crucial when we come to talk about reactions to Yersinia, Salmonella, Shigella, Chlamydia, and so on. Because these organisms are important in the acute stage we have no right to assume that they necessarily have anything to do with the long-term stages.

PROF. RUSSELL: Yes, but progression from acute to subacute may indeed be just a 'complication'.

PROF. W. MARTEL: Did I understand you to say that you were able to differentiate involvement of the apophyseal joint from the costrovetebral joints on the basis of the scans?

PROF. RUSSELL: Yes, but we don't, of course, have any anatomical basis for this.

PROF.MARTEL:They are rather close to one another.

PROF. RUSSELL: This, of course, is only on the tomoscan, not on the regular scan. But sometimes we can see two hot spots which appear like a dumb-bell, and we have presumed that one is the apophyseal and the adjacent one is costovertebral.

PROF. MARTEL: Do I understand correctly that in this series all of those that were scan-positive had abnormal sacroiliac joints radiologically?
PROF. RUSSELL: The reverse. There was one that had a positive radiograph but a negative scan. PROF. MARTEL: Any the other way?

PROF. RUSSELL: Yes, there were several with a positive scan and a negative $x$-ray picture. Even in retrospect the radiographs were negative.

PROF. A. E. GOOD: It is not too disturbing to learn that a number of patients negative for B27 had positive scans of the sacroiliac joints. With inflammatory bowel disease there is an appreciable group of patients negative for B27 with radiographic sacroiliitis perhaps related to the duration of severity of the bowel disease. The scans might be detecting other types of inflammatory or non-inflammatory involvement of the sacroiliac joints.

DR. E. ALBERT: In comparing radiological sacroiliitis and possible sacroiliitis as measured by scanning can it be said that radiology is a more accurate measure, with stronger association with B27, than is the scanning?

PROF. RUSSELL: $x$-ray pictures give you a historical interpretation of what has happened but the scan tells you what is happening. It is very clear that a pathological scan is not necessarily related to B27. As Professor Good has just pointed out, many patients who have clear-cut radiological sacroiliitis will be B27-negative, and it has even been suggested that some forms of sacroiliitis obviously do not relate to ankylosing spondylitis itself. As Dr. Hughes pointed out, some form of abnormal scan really does not relate to spondylitis in the conventional sense and I think this is another form of sacroiliac disorder. DR. CALIN: Several patients have persistent back pain but no sacroiliitis. The explanation for this pain may be insertional tendonitis at the many ligaments and muscles inserted around the pelvis and spine.

DR. ALBERT: Can I just follow up? As a mathematical measure is the correlation coefficient between an abnormal scan and B27 higher than between a radiologically positive sacroiliitis and $\mathrm{B} 27$ ?

PROF. RUSSELL: No.

PROF. T. BITTER: Looking for a 'specificity' of B27 it was disappointing enough to find definite AS without B27, yet more diasppointing to find that B27 did not 'code' for sacroiliitis. In fact, it has been just about everybody's experience that B27 correlates less with sacroliiitis than with AS. 